\title{
Health Inequities Among East and South Asian Gamblers During COVID-19: Key Risk Factors and Comorbidities
}

\author{
Alex Price ${ }^{1} \mathbb{D}$ \\ Accepted: 26 January 2022 \\ (c) The Author(s), under exclusive licence to Springer Science+Business Media, LLC, part of Springer Nature 2022
}

\begin{abstract}
Online gambling during COVID-19 has been associated with a variety of risk factors and comorbidities, such as co-occurring substance use, mental health problems, and financial concerns and gambling motives. Far less is known about these impacts on ethno-cultural populations, including East and South Asian gamblers. The present study has attempted to explore the health inequities related to these comorbidities and risk factors among East and South Asian gamblers.

A cross-sectional online survey of gamblers in Ontario, Canada, was carried out in August 2020 - a time when most land-based gambling venues were not operating at full capacity. Descriptive statistical analyses, odds ratios, and negative binomial regression (NBR) were used to compare East and South Asian gamblers to other online gamblers in Ontario.

The total survey sample of 2,012 gamblers included sub-samples of East Asian $(n=206)$ and South Asian gamblers $(n=107)$. Compared to other gamblers in Ontario, East and South Asians reported higher likelihood of severe gambling problems, risky financially focused gambling motives, gambling under the influence of alcohol, and elevated levels of mental health problems. An adjusted NBR analysis noted that East Asians were more highly involved in online gambling during the pandemic, compared to non-East Asian gamblers.
\end{abstract}

This study has presented an array of factors representing potential health inequities among East and South Asian gamblers during the pandemic. These findings merit further investigation and replication in order to inform the development of appropriate support resources.

Keywords East Asian · South Asian · Online gambling · COVID-19 · Mental health problems $\cdot$ Alcohol use $\cdot$ Health inequity

\section{Introduction}

Epidemiologic evidence has indicated that Asian populations in Western jurisdictions are disproportionately affected by the primary health impacts of the coronavirus disease pandemic of 2019 (COVID-19) (Moore et al., 2020; Wang et al., 2020). In contrast, very little

\section{Alex Price}

1 Centre for the Advancement of Best Practices, The Responsible Gambling Council, 205-411

Richmond Street East, Toronto, Ontario M5A 3S5, Canada 
is known about the comorbid secondary health impacts of the pandemic on Asian populations that may include addictive behaviors, substance use, mental health problems, and financial concerns. Online gambling has stood out as a reference point for highlighting the effects of addictive behaviors (Wardle et al., 2021) and comorbidities, including intoxicated gambling and elevated mental health problems as well as financial concerns and gambling motives attributed to COVID-19 (Håkansson, 2020; Price, 2020). These emergent findings raise questions about the specific comorbid health issues and risk factors that Asian gamblers may face during the pandemic.

On the topic of gambling risk and harm, as well as comorbid health factors potentially affecting Asian populations during COVID-19, promising (though limited) lines of inquiry can be drawn from (1) evidence prior to the pandemic, including attempts to distinguish East and South Asian gamblers; (2) general predictive behavioral risk factors during the pandemic; and (3) risk factors set apart from gambling that have shown comorbid associations in other Western populations.

\section{Potential Dimensions of Gambling-Related Harm}

The general dimensions of gambling harm may include financial impacts, relationship disruptions, mental health problems, decrements in physical health, cultural harms, work disruption, and criminal activity (Chan et al., 2016; Langham et al., 2016; Leung et al., 2010). Cultural harms, for instance, may include dissonance between gambling and cultural beliefs, impact on one's ability to participate in cultural activities or meet community expectations, and a resulting loss of connection and cohesion with the cultural community - shame, stigma, social isolation, and loss of identity are some of the potential manifestations of cultural harm (Langham et al., 2016).

\section{Gambling Among Asian Populations Prior to the Pandemic}

Prior to the pandemic, some studies have reported that Asian populations feature greater gambling engagement, both on land and online (Nower et al., 2017; Suissa, 2011). In other instances, Asian gamblers have reported losing more money from gambling than other ethno-cultural groups (Venkataraman Rinker et al., 2016). Above all else, the most consistent finding in the extant literature is that East Asians (e.g., Chinese, Japanese, Korean, and Taiwanese) and South Asians (e.g., East Indian, Pakistani, and Sri Lankan) are at higher risk for gambling problems and harms than non-Asian populations (Barry et al., 2009; J. Barry, 2014; Caler et al., 2017; Forrest \& Wardle, 2011; Kim, 2012; Ontario Resource Group on Gambling, 2010; Sobrun-Maharaj et al., 2013). Some research has also shown that immigrant and international student status can predict risk of problem gambling. For instance, some studies of Asian immigrants and international students in Westernized settings have indicated the use of dysfunctional coping strategies when dealing with settlement adversities that may include problematic gambling (Li et al., 2014; Sobrun-Maharaj et al., 2012; Thomas et al., 2011).

\section{Attempts to Distinguish East and South Asian Gamblers}

Differentiating East and South Asian gamblers is difficult, given the limited evidence available, but it is important to establish a more nuanced and incrementally less monolithic 
understanding of population health risk. Past research has highlighted a strong interest of some South Asian gamblers in card games, festival gambling during events (e.g., Diwali), and sports betting (Benegal, 2013; George et al., 2016). As with some gamblers in general populations, South Asians who experience problems with gambling may also be associated with lower educational attainment, substance use (i.e., tobacco, cannabis, and alcohol consumption), and mental health concerns (Fatima et al., 2019; George et al., 2016). Youth and young adults, in particular, have presented with high incidence of problem gambling (George et al., 2016; Jaisoorya et al., 2017). Research on East Asian gamblers has featured considerable attention on Chinese players in particular. In this context, gambling is perceived generally as a recreational and social activity, which may be introduced at a young age (i.e., under the age of 16) and is also common during holidays and family gatherings (Kam et al., 2017; Keovisai \& Kim, 2019; Kim, 2012; Yu \& Ma, 2019; Zheng et al., 2011). Limited evidence has also established an association between gambling problems and mental health concerns and substance overuse, which is to date better represented in general population studies (Cheung, 2014; El-Guebaly et al., 2006; Kong et al., 2011). Efforts to further understand differences as well as similarities between East and South Asian gamblers may help to inform the development of nuanced, targeted, and appropriate prevention and treatment interventions.

\section{General Population Risk Factors Apparent During the Pandemic}

Some predictive risk factors associated with problem gambling during COVID-19 have included substance co-use and intoxicated gambling, namely involving alcohol or cannabis consumption (Price, 2020). The related research literature examining Asian gamblers during the pandemic is very limited, however.

\section{Non-gambling Risk Factors Among Asian Populations During the Pandemic}

Research looking at other health risk factors among Asian populations, but not tied directly to gambling behaviors, have raised the question of whether comorbid associations with problem gambling may also be evident, as in the aforementioned general population study (Price, 2020). For instance, one study of non-gambling Chinese respondents during COVID-19 presented increased alcohol consumption alongside substantially increased Internet use and dependence (46.8\%) - though gaming and gambling were not used to characterize online activity (Sun et al., 2020). The pandemic has also depicted some ethno-cultural populations (i.e., African American, Asian, Hispanic, Native America, and other racialized groups) as being at greater risk for both excessive drinking and mental health problems during COVID-19, compared to White respondents (McPhee et al., 2020). Among Chinese coping with the pandemic, serious mental health problems may be mediated by coping response, with negative coping strategies aggravating emotional distress (Yan et al., 2021).

The present study attempts to contribute to knowledge pertaining to the secondary health impacts and risk factors associated with East and South Asian gamblers during COVID-19, relative to other Ontarian gamblers. Online gambling behaviors and risk status were examined in conjunction with gambling motives attributed to COVID-19, future landbased gambling intentions, indicators of mental health problems, financial concerns, and gambling under the influence of alcohol or cannabis. The purpose of this study is to present 
an incrementally less monolithic and more nuanced understanding of "Asian gamblers," during a unique centenary pandemic event.

\section{Methods}

In the summer of 2020 (August 1 to 19), a cross-sectional online survey of gamblers $(n=2,012)$ was conducted in Ontario, Canada. Amidst this sample were smaller cohorts of East Asians $(n=206)$ and South Asians $(n=107)$. The survey was administered at a time of substantial pandemic-related social and economic disruption, just following the lifting of a province-wide lockdown. The emergency lockdown measures resulted in the closure of most public gathering places and non-essential businesses as well as restrictions on nonhousehold gatherings of 5 or more people (Office of the Premier, 2020). Most land-based gambling facilities remained closed even after restrictions were lifted. Between July and December 2020, approximately $80 \%(n=23)$ of casinos briefly reopened at slightly different time-points in the province with limited capacity (e.g., 50 player limit, enhanced public health screening, no table games, and no food or beverage service) before closing again through the months of October to December, 2020.

\section{Participants and Data Collection}

Sample recruitment was provided by Delvinia, an online survey provider based in Toronto, Ontario. The sample was drawn from the vendor's AskingCanadians panel population of over one million Canadians. Recruits were directed to an online Qualtrics survey developed and administered by the research team. Those initiating the survey were first presented with an active and informed consent process prior to the first question as well as a detailed debriefing statement at the completion of the questionnaire. This survey received research ethics clearance from the Carleton University Research Ethics Board-B (project ID \#113,017). Those respondents who successfully completed the survey were compensated by Delvinia through various consumer points programs (e.g., Hudson Bay Company, Aeroplan, VIA Preference, and Petro Points).

Survey participants included adult gamblers (18 years and older) who resided in Ontario and reported gambling at least once in the past 12 months. In addition, sampling quotas were established to match provincial age and gender distributions. A total sample of 2,015 respondents completed the survey with three being excluded due to incomplete or missing responses to the question of ethno-cultural identity. The final study sample included 2,012 Ontarian gamblers, including smaller exploratory sub-samples of East Asians $(n=206$, $10.2 \%)$ and South Asians $(n=107,5.3 \%)$. East Asians were those who self-identified as Chinese, Japanese, Korean, Taiwanese, or Mongolian. South Asians included those who self-identified as East Indian, Pakistani, Sri Lankan, Afghani, Nepali, Bhutanese, Bangladeshi, or Maldivian. East and South Asian gamblers represented the largest ethno-cultural groups in the sample with the exception of White Europeans $(n=1,470,73.1 \%)$. The remainder of the study sample $(n=229,11.4 \%)$ included those self-identifying as Indigenous Canadian, Black, Latin American, Pacific Islander/Polynesian, Southeast Asian, West Asian, multi-ethnic, and other. These population groups were too small to examine as separate sub-samples and were aggregated along with White European gamblers. 


\section{Measures}

\section{Online Gambling}

Respondents were asked to report any online gambling engagement since land-based venues were first forced to close (March 17, 2020). Thirteen forms of online gambling were presented to respondents (see Tables 1 and 2). Respondents were also asked if their decision to gamble online was motivated by (1) COVID-19 social distancing measures and (2) a desire to earn income. In addition, survey respondents were asked to characterize their gambling engagement prior to COVID-19, be it online only, land-based only, or a mix of land-based and online play. Finally, participants reported on their future gambling intentions, once land-based venues were reopened (i.e., continue online only, switch to landbased only, or play both on land and online).

\section{Gambling Problems}

The Problem Gambling Severity Index (PGSI) was used to assess gambling risk (Ferris \& Wynne, 2001). This validated tool assesses gambling risk over the preceding 12 months of activity and includes nine items and four interpretive categories (Currie et al., 2013; Ferris \& Wynne, 2001; Lopez-Gonzalez et al., 2018). Based on a score out of 27, participants are assessed as either non-problem gambler (0), low-risk gambler (1-2), moderate-risk gambler (3-7), or high-risk problem gambler (8-27). From its inception to recent applications, the PGSI has demonstrated strong scale reliability (Cronbach's $\alpha \geq 0.84$ ) (Ferris \& Wynne, 2001; Price, 2020). In the present study, PGSI internal consistency was strong for the total sample $(\alpha=0.95)$ as well as among sub-samples of East Asians $(\alpha=0.97)$ and South Asians $(\alpha=0.96)$.

\section{Intoxicated Gambling}

Survey respondents were asked if they had ever gambled under the influence of an intoxicating substance during COVID-19 (since March 17, 2020). The available response options included alcohol, cannabis, other, and none.

\section{Mental Health Problems}

The Patient Health Questionnaire (PHQ-9) was administered to assess symptoms and severity of depression. The PHQ-9 has been derived from the Primary Care Evaluation of Mental Disorders (PRIME-ED) instrument and includes nine items from the depression criteria of the Diagnostic and Statistical Manual of Mental Disorders, fourth edition (DSM-4) (Homans, 2012; Kroenke et al., 2001). Based on scoring scale of 0 to 27, the PHQ-9 derives five interpretive categories, including minimal (0-4), mild (5-9), moderate (10-14), moderately severe (15-19), and severe (20-27). PHQ-9 internal consistency for this study was strong (total sample $\alpha=0.92$; East Asians $\alpha=0.94$; South East Asians $\alpha=0.94$ ).

The General Anxiety Disorder (GAD-7) Questionnaire was also included to assess mental health problems. It consists of seven items from the DSM-4 criteria for generalized anxiety disorder and is scored on a scale of 0 to 21 with four interpretive categories, 
Table 1 Key factors and comparison of East Asians and non-East Asians in Ontario

\begin{tabular}{|c|c|c|c|c|}
\hline \multirow[t]{2}{*}{ Factors } & \multirow{2}{*}{$\begin{array}{l}\text { East Asian gam- } \\
\text { blers }(n=206) \\
n(\%)\end{array}$} & \multicolumn{3}{|c|}{ Non-East Asian gamblers $(n=1,806)$} \\
\hline & & $n(\%)$ & OR & $95 \% \mathrm{CI}$ \\
\hline \multicolumn{5}{|l|}{ Gender $^{\mathrm{a}}$} \\
\hline Male & $107(51.9)$ & $922(51.1)$ & 1.04 & $0.78-1.38$ \\
\hline Female & $97(47.1)$ & $873(48.3)$ & 0.95 & $0.71-1.27$ \\
\hline \multicolumn{5}{|l|}{ Age } \\
\hline $18-24$ & $31(15.0)$ & $210(11.6)$ & 1.35 & $0.90-2.03$ \\
\hline $25-44$ & $102(49.5)$ & $549(30.4)$ & $2.25 * *$ & $1.68-3.00$ \\
\hline $45-64$ & $56(27.2)$ & $631(34.9)$ & $0.70^{*}$ & $0.50-0.96$ \\
\hline $65+$ & $17(8.3)$ & $416(23.0)$ & $0.30 * *$ & $0.18-0.50$ \\
\hline \multicolumn{5}{|c|}{ Typical gambling platform before COVID-19 } \\
\hline Online only & $38(19.4)$ & $200(11.8)$ & $1.80^{*}$ & $1.23-2.64$ \\
\hline Land-based only & $127(64.8)$ & $1331(78.4)$ & $0.51 * *$ & $0.37-0.69$ \\
\hline Mix of land and online & $31(15.8)$ & $166(9.8)$ & $1.73 *$ & $1.14-2.63$ \\
\hline \multicolumn{5}{|c|}{ Online gambling during COVID-19 } \\
\hline Instant lottery & $61(30.8)$ & $461(26.9)$ & 1.21 & $0.88-1.67$ \\
\hline Lottery draw & $116(58.3)$ & $956(55.6)$ & 1.12 & $0.83-1.50$ \\
\hline Sports lottery & $25(12.7)$ & $114(6.6)$ & $2.04 *$ & $1.29-3.24$ \\
\hline Raffles & $34(17.3)$ & $245(14.3)$ & 1.25 & $0.85-1.86$ \\
\hline Electronic gaming machines & $40(20.2)$ & $200(11.7)$ & $1.91 * *$ & $1.31-2.79$ \\
\hline Poker & $37(18.8)$ & $187(10.9)$ & $1.89 * *$ & $1.28-2.79$ \\
\hline Casino table games & $35(17.8)$ & $121(7.0)$ & $2.85 * *$ & $1.89-4.29$ \\
\hline Live sports betting & $24(12.2)$ & $98(5.7)$ & $2.29 * *$ & $1.43-3.68$ \\
\hline Sports pools & $34(17.3)$ & $166(9.7)$ & $1.96 * *$ & $1.31-2.93$ \\
\hline eSports betting & $24(12.2)$ & $49(2.9)$ & $4.75^{* *}$ & $2.84-7.93$ \\
\hline Virtual sports betting & $23(11.7)$ & $59(3.4)$ & $3.71 * *$ & $2.34-6.16$ \\
\hline Horse race betting & $18(9.1)$ & $92(5.4)$ & $1.77 *$ & $1.05-3.01$ \\
\hline Politics and novelty betting & $22(11.2)$ & $75(4.4)$ & $2.75 * *$ & $1.67-4.54$ \\
\hline \multicolumn{5}{|l|}{ Gambling motives } \\
\hline To earn income & $55(40.4)$ & $292(25.9)$ & $1.94 * *$ & $1.35-2.81$ \\
\hline Social distancing & $51(37.0)$ & $356(31.5)$ & 1.28 & $0.88-1.84$ \\
\hline \multicolumn{5}{|l|}{ Future gambling } \\
\hline Online & $34(17.1)$ & $155(9.0)$ & $2.09 * *$ & $1.39-3.12$ \\
\hline Land-based & 49 (24.6) & $643(37.3)$ & $0.55 * *$ & $0.39-0.77$ \\
\hline Both & $38(19.1)$ & $149(8.6)$ & $2.49 * *$ & $1.69-3.69$ \\
\hline \multicolumn{5}{|l|}{ Gambling problems (PGSI) } \\
\hline Non-problem & $111(56.1)$ & $1191(70.7)$ & $0.53 * *$ & $0.39-0.71$ \\
\hline Low risk & $30(15.2)$ & $243(14.4)$ & 1.06 & $0.70-1.60$ \\
\hline Moderate risk & $13(6.6)$ & $134(8.0)$ & 0.81 & $0.45-1.47$ \\
\hline Problem gambling & $44(22.2)$ & $117(6.9)$ & $3.83 * *$ & $2.61-5.62$ \\
\hline \multicolumn{5}{|c|}{ Intoxicated gambling during COVID-19 } \\
\hline Alcohol & $26(13.8)$ & $157(9.2)$ & $1.57 *$ & $1.00-2.44$ \\
\hline Cannabis & $15(8.8)$ & $78(5.4)$ & 1.69 & $0.95-3.01$ \\
\hline \multicolumn{5}{|l|}{ Anxiety (GAD-7) } \\
\hline No anxiety & $84(41.0)$ & $913(50.9)$ & $0.67 *$ & $0.50-0.90$ \\
\hline
\end{tabular}


Table 1 (continued)

\begin{tabular}{|c|c|c|c|c|}
\hline \multirow[t]{2}{*}{ Factors } & \multirow{2}{*}{$\begin{array}{l}\text { East Asian gam- } \\
\text { blers }(n=206) \\
n(\%)\end{array}$} & \multicolumn{3}{|c|}{ Non-East Asian gamblers $(n=1,806)$} \\
\hline & & $n(\%)$ & OR & $95 \% \mathrm{CI}$ \\
\hline Mild anxiety & $67(32.7)$ & $524(29.2)$ & 1.18 & $0.86-1.60$ \\
\hline Moderate anxiety & $38(18.5)$ & $220(12.3)$ & $1.63^{*}$ & $1.11-2.38$ \\
\hline Severe anxiety & $16(7.8)$ & $136(7.6)$ & 1.03 & $0.60-1.77$ \\
\hline \multicolumn{5}{|l|}{ Depression (PHQ-9) } \\
\hline No depression & $88(42.9)$ & $945(52.7)$ & $0.68^{*}$ & $0.51-0.91$ \\
\hline Mild depression & $59(28.8)$ & $452(25.2)$ & 1.2 & $0.87-1.65$ \\
\hline Moderate depression & $32(15.6)$ & $210(11.7)$ & 1.4 & $0.93-2.10$ \\
\hline Moderately severe depression & $18(8.8)$ & $124(6.9)$ & 1.3 & $0.77-2.17$ \\
\hline Severe depression & $8(3.9)$ & $63(3.5)$ & 1.12 & $0.53-2.63$ \\
\hline \multicolumn{5}{|l|}{ COVID-19 financial impacts } \\
\hline Lost employment & $17(8.3)$ & $147(8.1)$ & 1.01 & $0.60-1.71$ \\
\hline Work hours reduced & $33(16.0)$ & $233(12.9)$ & 1.29 & $0.87-1.91$ \\
\hline Negative impact on household income & $91(44.2)$ & $676(37.5)$ & 1.32 & $0.99-1.77$ \\
\hline
\end{tabular}

Note. The $n / \%$ values all reference total sub-samples for East Asians and non-East Asians; non-response and missing values may be reflected in counts

$O R$, odds ratio; $C I$, confidence interval; PGSI, Problem Gambling Severity Index; GAD-7, General Anxiety Disorder Questionnaire; $P H Q-9$, Patient Health Questionnaire

${ }^{*} p<0.05, * * p \leq 0.001$

${ }^{a}$ Three individuals identified as transgender, three preferred not to report gender, and seven reported other. Males and females represented $99.3 \%$ of the total study sample

including minimal (0-4), mild (5-9), moderate (10-14), and severe (15-21) (Spitzer et al., 2006). GAD-7 internal consistency was also strong for this study (total sample $\alpha=0.94$; East Asians $\alpha=0.94$; South East Asians $\alpha=0.94$ ).

\section{Financial Concerns}

In order to capture negative financial impacts attributed to COVID-19, two indicators were included in this study. Respondents were asked "Has your employment status changed as a result of COVID-19" with the options for lost employment and work hours reduced treated as the most severe impacts. Survey participants were also asked to respond to the statement "My household income has been negatively affected by COVID-19," which was ranked on a 7-point Likert scale from strongly disagree to strongly agree.

\section{Data Analysis}

Exploratory statistical analyses were first conducted to describe key variables, then to compare East and South Asians to other Ontarian gamblers, and finally to examine the level of gambling involvement between these groups. Bivariate analyses of key ethno-cultural groups involved chi-square tests $(p<0.05)$, odds ratio comparisons, and $95 \%$ confidence intervals. Negative binomial regression (NBR) analyses were also carried out to address over-dispersion in the data and test significant differences in the incidence of online 
Table 2 Key factors and comparison of South Asians and non-South Asians in Ontario

\begin{tabular}{|c|c|c|c|c|}
\hline \multirow[t]{2}{*}{ Factors } & \multirow[t]{2}{*}{$\begin{array}{l}\text { South Asian gam- } \\
\text { blers }(n=107)\end{array}$} & \multicolumn{3}{|c|}{$\begin{array}{l}\text { Non-South Asian gamblers }(n=1,905) \\
n(\%)\end{array}$} \\
\hline & & $n(\%)$ & OR & $95 \% \mathrm{CI}$ \\
\hline \multicolumn{5}{|l|}{ Gender $^{\mathrm{a}}$} \\
\hline Male & 67 (62.6) & $962(50.5)$ & $1.64^{*}$ & $1.10-2.45$ \\
\hline Female & $38(35.5)$ & $932(48.9)$ & $0.58^{*}$ & $0.38-0.86$ \\
\hline \multicolumn{5}{|l|}{ Age } \\
\hline $18-24$ & $29(27.1)$ & $212(11.1)$ & $2.97 * *$ & $1.89-4.65$ \\
\hline $25-44$ & $59(55.1)$ & $592(31.1)$ & $2.73^{* *}$ & $1.84-4.04$ \\
\hline $45-64$ & $12(11.2)$ & $675(35.4)$ & $0.23 * *$ & $0.13-0.42$ \\
\hline $65+$ & $7(6.5)$ & $426(22.4)$ & $0.24 * *$ & $0.11-0.53$ \\
\hline \multicolumn{5}{|c|}{ Typical gambling platform before COVID-19 } \\
\hline Online only & $16(15.7)$ & $222(12.4)$ & 1.32 & $0.76-2.28$ \\
\hline Land-based only & $57(55.9)$ & $1401(78.2)$ & $0.35^{* *}$ & $0.24-0.53$ \\
\hline Mix of land and online & $29(28.4)$ & $168(9.4)$ & $3.84 * *$ & $2.43-6.07$ \\
\hline \multicolumn{5}{|c|}{ Online gambling during COVID-19 } \\
\hline Instant lottery & 47 (45.6) & $475(26.3)$ & $2.36^{* *}$ & $1.58-3.52$ \\
\hline Lottery draw & $66(63.5)$ & $1006(55.5)$ & 1.40 & $0.93-2.10$ \\
\hline Sports lottery & $12(11.7)$ & $127(7.0)$ & 1.75 & $0.93-3.28$ \\
\hline Raffles & $13(12.6)$ & $266(14.7)$ & 0.84 & $0.46-1.52$ \\
\hline Electronic gaming machines & $23(22.3)$ & $217(12.0)$ & $2.11^{*}$ & $1.30-3.42$ \\
\hline Poker & $17(16.3)$ & 207 (11.4) & 1.51 & $0.88-2.60$ \\
\hline Casino table games & $15(14.4)$ & $141(7.8)$ & $2.00 *$ & $1.24-3.54$ \\
\hline Live sports betting & $10(9.6)$ & $112(6.2)$ & 1.61 & $0.82-3.18$ \\
\hline Sports pools & $14(13.5)$ & $186(10.3)$ & 1.36 & $0.76-2.43$ \\
\hline eSports betting & $6(5.8)$ & $67(3.7)$ & 1.59 & $0.67-3.76$ \\
\hline Virtual sports betting & $8(7.7)$ & $74(4.1)$ & 1.95 & $0.92-4.17$ \\
\hline Horse race betting & $13(12.5)$ & $97(5.4)$ & $2.52^{*}$ & $1.36-4.67$ \\
\hline Politics and novelty betting & $9(8.7)$ & $88(4.9)$ & 1.86 & $0.91-3.80$ \\
\hline \multicolumn{5}{|l|}{ Gambling motives } \\
\hline To earn income & $40(49.4)$ & $307(26.0)$ & $2.78^{* *}$ & $1.77-4.39$ \\
\hline Social distancing & $35(44.3)$ & $372(31.3)$ & $1.75^{*}$ & $1.10-2.77$ \\
\hline \multicolumn{5}{|l|}{ Future gambling intentions } \\
\hline Online & $9(8.7)$ & $180(9.9)$ & 0.86 & $0.43-1.74$ \\
\hline Land-based & $33(31.7)$ & $659(36.2)$ & 0.82 & $0.54-1.25$ \\
\hline Both & $20(19.2)$ & $167(9.2)$ & $2.35^{*}$ & $1.41-3.93$ \\
\hline \multicolumn{5}{|l|}{ Gambling problems (PGSI) } \\
\hline Non-problem & $49(48.0)$ & $1253(70.4)$ & $0.39 * *$ & $0.26-0.58$ \\
\hline Low risk & $17(16.7)$ & $256(14.4)$ & 1.19 & $0.70-2.04$ \\
\hline Moderate risk & $17(16.7)$ & $130(7.3)$ & $2.54^{*}$ & $1.47-4.41$ \\
\hline Problem gambling & $19(18.6)$ & $142(8.0)$ & $2.64 * *$ & $1.56-4.48$ \\
\hline \multicolumn{5}{|c|}{ Intoxicated gambling during COVID-19 } \\
\hline Alcohol & $17(16.7)$ & $166(9.3)$ & $1.95^{*}$ & $1.12-3.36$ \\
\hline Cannabis & $5(5.2)$ & $88(5.8)$ & 0.90 & $0.36-2.26$ \\
\hline
\end{tabular}


Table 2 (continued)

\begin{tabular}{|c|c|c|c|c|}
\hline \multirow[t]{2}{*}{ Factors } & \multirow[t]{2}{*}{$\begin{array}{l}\text { South Asian gam- } \\
\text { blers }(n=107)\end{array}$} & \multicolumn{3}{|c|}{$\begin{array}{l}\text { Non-South Asian gamblers }(n=1,905) \\
n(\%)\end{array}$} \\
\hline & & $n(\%)$ & OR & $95 \% \mathrm{CI}$ \\
\hline \multicolumn{5}{|l|}{ Anxiety (GAD-7) } \\
\hline None or minimal anxiety & $34(32.1)$ & $963(50.9)$ & $0.46^{* *}$ & $0.30-0.69$ \\
\hline Mild anxiety & $34(32.1)$ & $557(29.4)$ & 1.13 & $0.74-1.72$ \\
\hline Moderate anxiety & $22(20.8)$ & $236(12.5)$ & $1.84^{*}$ & $1.13-3.00$ \\
\hline Severe anxiety & $16(15.1)$ & $136(7.2)$ & $2.30^{*}$ & $1.31-4.02$ \\
\hline \multicolumn{5}{|l|}{ Depression (PHQ-9) } \\
\hline None or minimal depression & 37 (34.9) & $996(52.6)$ & $0.48 * *$ & $0.32-0.73$ \\
\hline Mild depression & $29(27.4)$ & $482(25.5)$ & 1.1 & $0.71-1.71$ \\
\hline Moderate depression & $16(15.1)$ & $226(11.9)$ & 1.31 & $0.76-2.27$ \\
\hline Moderately severe depression & $14(13.2)$ & $128(6.8)$ & $2.1^{*}$ & $1.16-3.79$ \\
\hline Severe depression & $10(9.4)$ & $61(3.2)$ & $3.13^{*}$ & $1.55-6.30$ \\
\hline \multicolumn{5}{|l|}{ COVID-19 financial impacts } \\
\hline Lost employment & $9(8.4)$ & $155(8.1)$ & 1.04 & $0.51-2.09$ \\
\hline Work hours reduced & $23(21.5)$ & $243(12.8)$ & $1.87^{*}$ & $1.16-3.02$ \\
\hline Negative impact on household income & 47 (43.9) & $720(37.8)$ & 1.29 & $0.87-1.91$ \\
\hline
\end{tabular}

Note. The $n / \%$ values all reference total sub-samples for South Asians and non-South Asians; non-response and missing values may be reflected in counts

$O R$, odds ratio; $C I$, confidence interval; PGSI, Problem Gambling Severity Index; GAD-7, General Anxiety Disorder Questionnaire, $P H Q-9$, Patient Health Questionnaire

${ }^{*} p<0.05,{ }^{* *} p \leq 0.001$

${ }^{a}$ Three individuals identified as transgender, three preferred not to report gender, and seven reported other. Males and females represented $99.3 \%$ of the total study sample

gambling involvement during the period of study (Allison \& Waterman, 2002). The NBR analyses for both East and South Asian gamblers first involved sets of univariate incident rate ratios and then adjusted models controlling for age and gender.

\section{Results}

\section{Online Gambling Behavior and Motivations}

Descriptive statistics and odds ratio comparisons for East and South Asian gamblers can be found in Tables 1 and 2, respectively. Prior to COVID-19, East Asian gamblers were more likely to gamble online only $(n=38,19.4 \%$; $\mathrm{OR}=1.80, p<0.05)$ and play mix of online and land-based games $(n=31,15.8 \%$; OR $=1.73, p<0.05)$. During the study period, this group reported significantly greater online gambling engagement in all types of games, compared to other Ontarian gamblers, with the exceptions of instant lottery, lottery draws, and raffles. During the pandemic, being motivated to gamble online to earn income was nearly twice as likely $(n=55,40.4 \%$; OR $=1.94, p \leq 0.001)$ relative to non-East Asians. Looking forward to the prospect of land-based gambling venues reopening, East Asian gamblers were much more likely to express the intentions of either continuing to gamble 
online exclusively $(n=34,17.1 \% ; \mathrm{OR}=2.09, p \leq 0.001)$ or gamble both online and on land $(n=38,19.1 \%$; OR $=2.49, p \leq 0.001)$.

South Asian gamblers were nearly four times as likely to gamble both online and on land prior to the pandemic $(n=29,28.4 \%$; OR $=3.84, p \leq 0.001)$, compared to non-South Asians. This behavioral profile was consistent with the intention of this group to gamble both online and on land when in-person venues reopened $(n=20,19.2 \%$; OR $=2.35$, $p<0.05)$. At the time of data collection, instant lottery $(n=47,45.6 \%$; OR $=2.36$, $p \leq 0.001)$, electronic gaming machines $(n=23,22.3 \%$; OR $=2.11, p<0.05)$, casino table games $(n=15,14.4 \%$; OR $=2.00, p<0.05)$, and horse race betting $(n=13,12.5 \%$; $\mathrm{OR}=2.52, p<0.05)$ stood out as the forms of online gambling with the most significant increased odds of South Asian participation, relative to non-South Asian gamblers. South Asian gamblers also reported increased likelihood of gambling online to earn income $(n=40,49.4 \%$; OR $=2.78, p \leq 0.001)$ and as a response to social distancing measures $(n=35,44.3 \%$; OR $=1.75, p<0.05)$ introduced during COVID-19, compared to other Ontarian gamblers.

\section{Gambling Problems and Other Risk Factors}

East Asian gamblers stood out with a far greater likelihood of high-risk problem gambling status and a far lower likelihood of non-problem gambling status. Increased odds of gambling online under the influence of alcohol was also apparent among East-Asians $(n=26$, 13.8\%; OR $=1.57, p<0.05$ ). Over one-quarter of East Asian gamblers reported moderate to severe anxiety (26.3\%) and depression (28.3\%), with significantly increased odds of moderate anxiety $(n=38,18.5 \%$; OR $=1.63, p<0.05)$, compared to non-East Asians. Reduced work hours $(n=33,16 \%)$ and negative impact on household income $(n=91$, $44.2 \%$ ), attributed to COVID-19, were notable in proportion but not significant in comparison with non-East Asian gamblers.

South Asian gamblers had over twice the odds of being positively screened for moderate-risk $(n=17,16.7 \%$; OR $=2.54, p<0.05)$ and high-risk problem gambling $(n=19$, $18.6 \%$; OR $=2.64, p \leq 0.001$ ), compared to non-South Asians. The odds of online gambling under the influence of alcohol was two-times that of other Ontarian gamblers $(n=17$, 16.7\%; OR $=1.95, p<0.05$ ). South Asian gamblers also reported significantly increased likelihood $(p<0.05)$ of elevated levels of anxiety and depression, as noted in Table 2. They were also more likely to experience reduced work hours $(n=23,21.5 \%$; OR $=1.87$, $p<0.05)$ and a substantial proportion reported some degree of negative impact on household income due to COVID-19 (43.9\%).

\section{Negative Binomial Regressions of Online Gambling Involvement}

The NBR analyses of online gambling involvement for East and South Asians, as indicated by the number of online games engaged in since land-based gambling opportunities practically ceased (March 17, 2020), is depicted in Table 3. In the unadjusted analyses, East Asian and South Asian gamblers had higher incidence rates of online gambling involvement than other Ontarian gamblers. After adjusting for age and gender, only East Asian gamblers maintained a significantly higher rate of involvement (IRR $=1.35 ; 95 \% \mathrm{CI}$ : $1.13-1.62, p=0.001)$. 
Table 3 Negative binomial regressions of East and South Asians and online gambling involvement in Ontario

\begin{tabular}{lllll}
\hline Factors & Unadjusted & \multicolumn{4}{l}{ Adjusted for age and gender } \\
\cline { 4 - 5 } & IRR $(95 \% \mathrm{CI})$ & $p$ & IRR (95\% CI) & $p$ \\
\hline East Asian gamblers & $1.51(1.27-1.81)$ & $<0.001$ & $1.35(1.13-1.62)$ & 0.001 \\
South Asian gamblers & $1.39(1.10-1.75)$ & 0.005 & $1.13(0.88-1.44)$ & 0.350 \\
\hline
\end{tabular}

Note. $I R R$, incidence rate ratio; $C I$, confidence interval

\section{Discussion}

This study has shown that East and South Asian gamblers in Ontario do experience a variety of comorbid health inequities, relative to other gamblers in the province. These inequities related to online gambling risks, intoxicated gambling, mental health problems, and, to a lesser degree, financial concerns.

Risk from online gambling can be highly variable and contextual, taking into account the degree of involvement and spending that may be moderated by certain types of games shown to be associated with higher gambling risk outcomes. Electronic gaming machines, live sports betting, some casino table games, horse racing, and others stand out as examples of riskier forms of online gambling activities (Dragicevic et al., 2011; Hing et al., 2017). Generally, East Asians appeared to have the highest odds for severe gambling problems, which was complemented by a higher likelihood of engaging in most online games, including those considered to be high risk for problems (i.e., electronic gaming machines, live sports betting, and horse race betting). South Asian gamblers also reported increased odds of moderate-risk and high-risk problem gambling, though differences in their online gambling activities, relative to other Ontarian gamblers, focused mainly on instant lottery, electronic gaming machines, casino table games, and horse race betting.

Some studies have also noted that online gambling may not be an independent predictor of gambling risk and that those who experience gambling problems have a greater tendency to be involved in many forms of gambling, both online and on land (Gainsbury et al., 2014; Wardle et al., 2011). This point was reflected by an increased tendency of both East and South Asians gamblers to report gambling both online and on land prior to COVID-19 and the intention of approximately $20 \%$ of both groups to do so once land-based gambling venues reopened fully. Further investigation is required to assess the influence that low awareness of responsible gambling information and problem gambling services, and the impact of shame and stigma have on gambling-related harms - the latter two factors pertaining to cultural harms, specifically (Ontario Resource Group on Gambling, 2010; Papineau, 2013; Tong et al., 2019). In addition, there is also reasonable grounds to emphasize the need for more research on cultural factors affecting gambling problems and comorbidities that may inform the development of culturally appropriate support resources (Raylu \& Oei, 2004; Suissa, 2011).

Financially motivated gambling is highly predictive of gambling risk and problems (Dechant, 2014; Lee et al., 2007; Nower \& Blaszczynski, 2010; Tabri et al., 2020). The present study has provided additional evidence of this dynamic within the context of East and South Asian gamblers during COVID-19. Specifically, gambling online to earn income was a motive endorsed by over $40 \%$ of East and South Asian gamblers and was twice or more likely to present in these groups, compared to other Ontarian gamblers. Not 
only did this reflect a substantial monetary focus on what is meant to be a recreational activity, it was strongly associated with problem gambling. One might speculate that this motivational focus has been inflamed by the substantial economic disruptions caused by the pandemic. However, East and South Asian gamblers did not suffer disproportionate employment losses or negative impact on household income compared to other Ontarian gamblers, though the latter did exceed $40 \%$ in both groups. Though this study did not capture household income level or immigrant status, it may still be valuable to consider the potential economic impacts of COVID-19 on East and South Asian gamblers. For instance, Canada's national statistics agency notes that low-income rates among recent immigrants is typically much higher than Canadian-born residents (Picot \& Hou, 2014), calling attention to evidence of the disproportionate impact of problem gambling among low-income groups in Canada (van der Maas, 2016). As such, endorsing a strong financial motivation to gamble may be influenced by other factors not assessed in this study. Previous studies have also shown significant associations between financial motivations and materialism among Chinese gamblers with gambling problems and potentially reflect cultural values that are comorbidly associated with risky gambling behaviors (Netemeyer et al., 1998; Tao et al., 2011; Wu et al., 2012). Far less is known about other East Asian sub-groups and South Asian gamblers, more generally.

Intoxicated online gambling has not been an extensively studied topic, especially in relation to ethno-cultural differences. This investigation found that gambling under the influence of alcohol was somewhat prevalent (14-16\%) and more likely among East and South Asian gamblers. Similar evidence from high-risk online gamblers in Australia has also noted significantly increased occurrences of alcohol co-use as well as psychological distress (Hing et al., 2017). More recent investigations examining respondents in China have identified patterns of comorbid addictive behaviors involving Internet use and dependence and increased alcohol consumption, which have been interpreted as a form of maladaptive coping during COVID-19 (Sun et al., 2020).

Problematic mental health inequities did not appear similarly distributed between East and South Asian gamblers. Only moderate anxiety appeared significantly more likely among East Asian gamblers, compared to non-East Asian gamblers. In contrast, South Asian gamblers had approximately twice or more the odds of moderate and severe anxiety and moderately severe and severe depression, when compared to other Ontarian gamblers. Despite these differences, evidence from gambling prevalence data in Canada has indicated that symptoms of mental health problems are more likely to manifest in those experiencing gambling problems, which also identified South Asians as a vulnerable population, and has now been established in the present study with added nuance (Barry, 2014). In reference to maladaptive coping and addictive behaviors, which was noted previously, other studies have also indicated that mental health problems among Chinese populations may be mediated by coping responses, with risky strategies lending themselves to intensifying emotional distress (Li et al., 2014; Yan et al., 2021).

\section{Limitations}

This study features several limitations. For one, the constructs of East and South Asian gamblers may not capture important distinctions between disaggregated ethno-cultural groups. This decision represented a compromise between sample size and depth of ethnocultural distinction. Despite this limitation, the study has taken a step past previous ones that have used a single monolithic "Asian" category to characterize distinct ethno-cultural 
populations. In addition, the survey itself is cross-sectional and relied upon self-reported feedback, which is prone to response bias. Also, the study's exploratory convenience sample may not be generalizable to the East and South Asian populations in Ontario. With regard to the odds ratio comparisons, no adjustments were made for age or gender. Moreover, sample sizes for East and South Asian cohorts were also small, which may have limited the statistical power necessary to confirm certain phenomena, such as increased incidence of South Asian gambling involvement in the NBR analysis. Indeed, due to the small sample sizes and the unequal variance in the data, additional analyses of financially focused motivation were abandoned due to the potential loss of statistical power.

\section{Conclusions}

This study represents one of the first to examine the holistic impacts of online gambling behavior and risk alongside intoxicated gambling, mental health problems, and financial concerns among East and South Asian gamblers during COVID-19. It provides a partial and incremental understanding of the relationship between key factors, comorbidities, and gambling risk during an early period of the pandemic, among two distinct gambling population groups. The findings have reaffirmed the disproportionate risk for gambling problems and other comorbidities experienced by these ethno-cultural groups and have presented an array of risk factors that would benefit from further investigation. By extension, this study has implied a potential need for greater focused attention on health promotion and support resources tailored to East and South Asian gamblers. Future studies may also be well served by a more nuanced examination of gambling comorbidities among these and other ethno-cultural groups that take into account migration history. In addition, the protective effects on employment disruption and negative impact on household income experienced by these sampled population groups, relative to other Ontarians, merit further study.

Acknowledgements The author acknowledges the technical support of Silas Xuereb and Mackenzie Dowson related to survey administration. Broader research collaboration and analytical discourse including Drs. Michael Wohl, Nassim Tabri, Sasha Stark, and Iris Balodis are also acknowledged and appreciated.

Funding This study was funded through a COVID-19 Rapid Response Research Grant (\#RSGRANT185594) awarded by Carleton University.

\section{Declarations}

Conflict of Interest [Note: statement is not included in blinded manuscript due to author-identifying information].

The author is employed by the Responsible Gambling Council (RGC), a not-for-profit organization, as a Senior Researcher. The second wave data presented in this manuscript was developed in partnership with members of the Ontario Gambling Research Society, of which the author is a member. This study received a COVID-19 Rapid Response Research Grant (\#RSGRANT185594) from Carleton University on which the author is a co-investigator. The RGC has also allocated funding for the first wave of this study, which aimed to conduct program needs assessment as part of its community outreach and prevention program, which was funded by the Ontario Ministry of Health and Long-Term Care.

\section{References}

Allison, P. D., \& Waterman, R. P. (2002). Fixed-effects negative binomial regression models. Sociological Methodology, 32(1), 247-265. https://doi.org/10.1111/1467-9531.00117 
Barry, D. T., Steinberg, M. A., Wu, R., \& Potenza, M. N. (2009). Differences in characteristics of Asian American and white problem gamblers calling a gambling helpline. CNS Spectrums, 14(2), 83-91. https://doi.org/10.1109/TMI.2012.2196707.Separate

Barry, J. (2014). 2014 British Columbia Problem Gambling Prevalence Study. Gaming Policy and Enforcement Branch, Ministry of Finance. Retrieved from https://www2.gov.bc.ca/assets/gov/sports-recre ation-arts-and-culture/gambling/gambling-in-bc/reports/rpt-rg-prevalence-study-2014.pdf

Benegal, V. (2013). Gambling experiences, problems and policy in India: A historical analysis. Addiction, 108(12), 2062-2067. https://doi.org/10.1111/j.1360-0443.2012.04068.x

Caler, K. R., Vargas Garcia, J. R., \& Nower, L. (2017). Problem gambling among ethnic minorities: Results from an epidemiological study. Asian Journal of Gambling Issues and Public Health, 7(1), 7. https:// doi.org/10.1186/s40405-017-0027-2

Chan, E. M., Lo, D., \& N. A., Jackson, A. C., \& Shek, D. T. (2016). Gambling related family coping and the impact of problem gambling on families in Hong Kong. Asian Journal of Gambling Issues and Public Health, 6(1), 1-12. https://doi.org/10.1186/s40405-016-0009-9

Cheung, N. W. T. (2014). Low self-control and co-occurrence of gambling with substance use and delinquency among Chinese adolescents. Journal of Gambling Studies, 30(1), 105-124. https://doi.org/10. 1007/s10899-012-9351-8

Currie, S. R., Hodgins, D. C., \& Casey, D. M. (2013). Validity of the Problem Gambling Severity Index interpretive categories. Journal of Gambling Studies, 29(2), 311-327. https://doi.org/10.1007/ s10899-012-9300-6

Dechant, K. (2014). Show me the money: Incorporating financial motives into the Gambling Motives Questionnaire. Journal of Gambling Studies, 30, 949-965. https://doi.org/10.1007/s10899-013-9386-5

Dragicevic, S., Tsogas, G., \& Kudic, A. (2011). Analysis of casino online gambling data in relation to behavioural risk markers for high-risk gambling and player protection. International Gambling Studies, 11(3), 377-391. https://doi.org/10.1080/14459795.2011.629204

El-Guebaly, N., Patten, S. B., Currie, S., Williams, J. V. A., Beck, C. A., Maxwell, C. J., \& Wang, J. L. (2006). Epidemiological associations between gambling behavior, substance use \& mood and anxiety disorders. Journal of Gambling Studies, 22(3), 275-287. https://doi.org/10.1007/s10899-006-9016-6

Fatima, S., Jamil, M., \& Ardila, A. (2019). Cognitive control and criminogenic cognitions in South Asian gamblers. Journal of Gambling Studies, 35(2), 501-516. https://doi.org/10.1007/s10899-018-9805-8

Ferris, J., \& Wynne, H. (2001). The Canadian Problem Gambling Index: Final report. Ottawa, Ontario. Retrieved from https://www.greo.ca/Modules/EvidenceCentre/files/Ferrisetal(2001)The_Canadian_ Problem_Gambling_Index.pdf. Accessed 28 Jan 2022

Forrest, D., \& Wardle, H. (2011). Gambling in Asian communities in Great Britain. Asian Journal of Gambling Issues and Public Health, 2, 2-16. https://doi.org/10.1186/BF03342121

Gainsbury, S. M., Russell, A., Wood, R., Hing, N., \& Blaszczynski, A. (2014). How risky is Internet gambling? A comparison of subgroups of Internet gamblers based on problem gambling status. New Media \& Society. https://doi.org/10.1177/1461444813518185

George, S., Jaisoorya, T., Nair, S., Rani, A., Menon, P., Madhavan, R., ... Petry, N. M. (2016). A crosssectional study of problem gambling and its correlates among college students in South India. BJPsych Open, 2(3), 199-203. https://doi.org/10.1192/bjpo.bp.115.002519

Håkansson, A. (2020). Changes in gambling behavior during the COVID-19 pandemic: A web survey study in Sweden. International Journal of Environmental Research and Public Health, 17(4013), 1-16. https://doi.org/10.3390/ijerph17114013

Hing, N., Russell, A. M., \& Browne, M. (2017). Risk Factors for Gambling Problems on Online Electronic Gaming Machines, Race Betting and Sports Betting. Frontiers in Psychology, 8(MAY), 1-15. https:// doi.org/10.3389/fpsyg.2017.00779

Homans, W. (2012). The validity of the PHQ-9 and the GAD-7 for screening depressive and anxiety disorders in sick-listed workers. Utrecht University.

Jaisoorya, T. S., Beena, K. V., Beena, M., Ellangovan, K., Thennarassu, K., Bowden-Jones, H., ... George, S. (2017). Do high school students in India Gamble? A study of problem gambling and its correlates. Journal of Gambling Studies, 33(2), 449-460. https://doi.org/10.1007/s10899-016-9651-5

Kam, S. M., Wong, I. L. K., So, E. M. T., Un, D. K. C., \& Chan, C. H. W. (2017). Gambling behavior among Macau college and university students. Asian Journal of Gambling Issues and Public Health, 7(1), 2. https://doi.org/10.1186/s40405-017-0022-7

Keovisai, M., \& Kim, W. (2019). "It's not officially gambling": Gambling perceptions and behaviors among older Chinese immigrants. Journal of Gambling Studies, (0123456789). https://doi.org/10.1007/ s10899-019-09841-4

Kim, W. (2012). Acculturation and gambling in Asian Americans: When culture meets availability. International Gambling Studies, 12(1), 69-88. https://doi.org/10.1080/14459795.2011.616908 
Kong, G., Tsaia, J., Pilverc, C. E., Tan, H. S., Hoff, R. A., Cavallo, D., ... Potenza, M. N. (2011). Differences in gambling problem severity and gambling and health/functioning characteristics among Asian-American and Caucasian high-school students. Bone, 23(1), 1-7. https://doi.org/10.1016/j. psychres.2013.10.005

Kroenke, K., Spitzer, R. L., \& Williams, J. B. (2001). The PHQ-9: Validity of a brief depression severity measure. Journal of General Internal Medicine, 16(9), 606-613. https://doi.org/10.1046/j.15251497.2001.016009606.x

Langham, E., Thorne, H., Browne, M., Donaldson, P., Rose, J., \& Rockloff, M. (2016). Understanding gambling related harm: A proposed definition, conceptual framework, and taxonomy of harms. BMC Public Health, 16(1), 80. https://doi.org/10.1186/s12889-016-2747-0

Lee, H. P., Chae, P. K., Lee, H. S., \& Kim, Y. K. (2007). The five-factor gambling motivation model. Psychiatry Research, 150(1), 21-32. https://doi.org/10.1016/j.psychres.2006.04.005

Leung, K. C., Wong, I. L. K., Lau, K. M., \& Yeung, S. C. (2010). Stress, health and coping resources of Chinese pathological gamblers' spouses. Asian Journal of Gambling Issues and Public Health, 1(1), 61-74. https://doi.org/10.1186/BF03342119

Li, W., Tse, S., \& Chong, M. D. (2014). Why Chinese international students gamble: Behavioral decision making and its impact on identity construction. International Journal of Mental Health and Addiction, 12(3), 321-334. https://doi.org/10.1007/s11469-013-9456-z

Lopez-Gonzalez, H., Estévez, A., \& Griffiths, M. D. (2018). Spanish validation of the Problem Gambling Severity Index: A confirmatory factor analysis with sports bettors. Journal of Behavioral Addictions, 7(3), 814-820. https://doi.org/10.1556/2006.7.2018.84

McPhee, M. D., Keough, M. T., Rundle, S., Heath, L. M., Wardell, J. D., \& Hendershot, C. S. (2020). Depression, environmental reward, coping motives and alcohol consumption during the COVID-19 pandemic. Frontiers in Psychiatry, 11(October), 1-14. https://doi.org/10.3389/fpsyt.2020.574676

Moore, J., Ricaldi, J., Rose, C., Fuld, J., Parise, M., Kang, G., ... Honein, M. (2020). Disparities in incidence of COVID-19 among underrepresented racial/ethnic groups in counties identified as hotspots during June 5-18, 2020 - 22 States, February-June 2020. MMWR. Morbidity and Mortality Weekly Report, 69(33), 1122-1126. Retrieved from https://pubmed.ncbi.nlm.nih.gov/32817602/. Accessed 28 Jan 2022

Netemeyer, R. G., Burton, S., Cole, L. K., Williamson, D. A., Zucker, N., Bertman, L., \& Diefenbach, G. (1998). Characteristics and beliefs associated with probable pathological gambling: A pilot study with implications for the national gambling impact and policy commission. Journal of Public Policy and Marketing, 17(2), 147-160. https://doi.org/10.1177/074391569801700201

Nower, L., \& Blaszczynski, A. (2010). Gambling motivations, money-limiting strategies, and precommitment preferences of problem versus non-problem gamblers. Journal of Gambling Studies, 26(3), 361-372. https://doi.org/10.1007/s10899-009-9170-8

Nower, L., Volberg, R., \& Caler, K. (2017). The prevalence of online and land-based gambling in New Jersey. New Brunswick, New Jersey. https://doi.org/10.13140/RG.2.2.23295.41127

Office of the Premier. (2020). Ontario prohibits gatherings of more than five people with strict exceptions. Toronto: Government of Ontario. Retrieved from https://news.ontario.ca/opo/en/2020/03/ ontario-prohibits-gatherings-of-five-people-or-more-with-strict-exceptions.html. Accessed 28 Jan 2022

Ontario Resource Group on Gambling. (2010). A guide for counsellors: Working with problem gambling clients from ethno-cultural communities. Toronto, Ontario: Ontario Ministry of Health and Long-Term Care. Retrieved from http://icboc.ca/wp-content/uploads/2020/02/A-Guide-for-Couns ellors-Working-with-Problem-Gambling-Clients-from-Ethno-Cultural-Communities.pdf. Accessed 28 Jan 2022

Papineau, E. (2013). The expansion of electronic gambling machines in China through anthropological and public health lenses. Asian Journal of Gambling Issues and Public Health, 3(1), 1-12. https:// doi.org/10.1186/2195-3007-1-3

Picot, G., \& Hou, F. (2014). Immigration, low income and income inequality in Canada: What's new in the 2000s? Ottawa, Ontario. Retrieved from https://www150.statcan.gc.ca/n1/en/pub/11f0019m/ $11 \mathrm{f} 0019 \mathrm{~m} 2014364$-eng.pdf?st=ax6kvl2O. Accessed 28 Jan 2022

Price, A. (2020). Online Gambling in the Midst of COVID-19: A nexus of mental health concerns, substance use and financial stress. International Journal of Mental Health and Addiction. https://doi. org/10.1007/s11469-020-00366-1

Raylu, N., \& Oei, T. P. (2004). Role of culture in gambling and problem gambling. Clinical Psychology Review, 23(8), 1087-1114. https://doi.org/10.1016/j.cpr.2003.09.005

Sobrun-Maharaj, A., Rossen, F., \& Wong, A. S. (2012). The impact of gambling and problem gambling on Asian families and communities in New Zealand. Ministry of Health. Wellington, New 
Zealand.Retrieved from https://www.fmhs.auckland.ac.nz/assets/fmhs/soph/sch/cahre/docs/Final\% 20IGAF\%20report\%202012.pdf

Sobrun-Maharaj, A., Rossen, F., \& Wong, A. S. (2013). Negative impacts of gambling on Asian Families and communities in New Zealand. Asian Journal of Gambling Issues and Public Health, 3(14), $1-16$.

Spitzer, R. L., Kroenke, K., Williams, J. J. B. W., \& Lo, B. (2006). A brief measure for assessing generalized anxiety disorder: The GAD-7. Archives of Internal Medicine, 166(10), 1092-1099. https://doi.org/ 10.1001/archinte.166.10.1092

Suissa, A. J. (2011). Vulnerability and gambling addiction: Psychosocial benchmarks and avenues for intervention. International Journal of Mental Health and Addiction, 9(1), 12-23. https://doi.org/10.1007/ s11469-009-9248-7

Sun, Y., Li, Y., Bao, Y., Meng, S., Sun, Y., Schumann, G., ... Shi, J. (2020). Increased addictive internet and substance use behavior during the COVID-19 pandemic in China. American Journal on Addictions, 29, 268-270. https://doi.org/10.1111/ajad.13066

Tabri, N., Xuereb, S., Cringle, N., \& Clark, L. (2020). Revisiting the role of financial motives in disordered gambling: A meta-analytic review. Preprint. https://doi.org/10.31234/osf.io/9tnm7

Tao, V. Y. K., Wu, A. M. S., Cheung, S. F., \& Tong, K. K. (2011). Development of an indigenous inventory GMAB (Gambling Motives, Attitudes and Behaviors) for Chinese gamblers: An exploratory study. Journal of Gambling Studies, 27(1), 99-113. https://doi.org/10.1007/s10899-010-9191-3

Thomas, A., Moore, S., Kale, S., Zlatevska, N., Spence, M., Staiger, P., ... Kyrios, M. (2011). International student gambling: The role of acculturation, gambling cognition and social circumstances. Australia. Retrieved from https://pure.bond.edu.au/ws/portalfiles/portal/25258175/International_student_gambl ing.pdf. Accessed 28 Jan 2022

Tong, K. K., Chen, J. H., \& Wu, A. M. S. (2019). Application of health belief model to practice of responsible gambling. Journal of Gambling Studies, 35(3), 1047-1062. https://doi.org/10.1007/ s10899-019-09871-y

van der Maas, M. (2016). Problem gambling, anxiety and poverty: An examination of the relationship between poor mental health and gambling problems across socio-economic status. International Gambling Studies, 16(2), 281-295. https://doi.org/10.1080/14459795.2016.1172651

Venkataraman Rinker, D., Rodrigues, L., Krieger, H., \& Neighbors, C. (2016). Racial and ethnic differences in problem gambling among college students. Racial and Ethnic Differences in Problem Gambling among College Students, 32. https://doi.org/10.1007/s10899-015-9563-9

Wang, D., Gee, G. C., Bahiru, E., Yang, E. H., \& Hsu, J. J. (2020). Asian-Americans and Pacific Islanders in COVID-19: Emerging disparities amid discrimination. Journal of General Internal Medicine, 35(12), 3685-3688. https://doi.org/10.1007/s11606-020-06264-5

Wardle, H., Donnachie, C., Critchlow, N., Brown, A., Bunn, C., Dobbie, F., ... Hunt, K. (2021). The impact of the initial Covid-19 lockdown upon regular sports bettors in Britain: Findings from a cross-sectional online study. Addictive Behaviors, 118(November 2020), 106876. https://doi.org/10.1016/j.addbeh. 2021.106876

Wardle, H., Moody, A., Griffiths, M., Orford, J., \& Volberg, R. (2011). Defining the online gambler and patterns of behaviour integration: Evidence from the British Gambling Prevalence Survey 2010. International Gambling Studies, 11(3), 339-356. https://doi.org/10.1080/14459795.2011.628684

Wu, A. M. S., Tao, V. Y. K., Tong, K., \& kit, \& Cheung, S. F. (2012). Psychometric evaluation of the inventory of Gambling Motives, Attitudes and Behaviours (GMAB) among Chinese gamblers. International Gambling Studies, 12(3), 331-347. https://doi.org/10.1080/14459795.2012.678273

Yan, L., Gan, Y., Ding, X., Wu, J., \& Duan, H. (2021). The relationship between perceived stress and emotional distress during the COVID-19 outbreak: Effects of boredom proneness and coping style. Journal of Anxiety Disorders, 77(January), 1-12. https://doi.org/10.1016/j.janxdis.2020.102328

Yu, L., \& Ma, C. M. S. (2019). Youth gambling in Hong Kong: Prevalence, psychosocial correlates, and prevention. Journal of Adolescent Health, 64(6), S44-S51. https://doi.org/10.1016/j.jadohealth.2018. 09.019

Zheng, W. Y., Walker, M., \& Blaszczynski, A. (2011). Mahjong and problem gambling in Sydney: An exploratory study with Chinese Australians. Journal of Gambling Issues, 25, 24. https://doi.org/10. 4309/jgi.2011.25.3

Publisher's Note Springer Nature remains neutral with regard to jurisdictional claims in published maps and institutional affiliations. 